\title{
Hubungan Pola Makan dengan Kejadian Depresi pada Penderita Dispepsia Fungsional
}

\author{
Yuriko Andre, Rizanda Machmud, Arina Widya Murni
}

\begin{abstract}
Abstrak
Ketidakteraturan makan seperti kebiasaan makan yang buruk, tergesa-gesa, dan jadwal yang tidak teratur dapat menyebabkan dispepsia. Penderita depresi harus ditangani dengan sungguh-sungguh karena dikhawatirkan penderita depresi sangat tidak memperhatikan kesehatan dirinya seperti tidak mematuhi pola makan atau pola makannya menjadi tidak teratur. Penelitian ini bertujuan untuk mengetahui hubungan pola makan dengan kejadian depresi pada penderita dispepsia fungsional. Penelitian bersifat analitik dengan desain cross sectional. Subjek penelitian adalah 40 orang penderita dispepsia fungsional. Penelitian dilakukan di kota Padang dengan menggunakan data pasien dispepsia fungsional bulan Januari-Desember 2011. Pengumpulan data dilakukan pada periode JuniNovember 2012 dan pengolahan data dilakukan dengan uji korelasi menggunakan sistem komputerisasi. Hasil penelitian didapatkan nilai peluang Odd Ratio (OR) dengan Confidence Interval (CI) 95\% pada penderita depresi berpeluang sebesar 4.500 kali lebih besar memiliki pola makan tidak teratur dibandingkan dengan tidak depresi serta menunjukkan derajat hubungan yang cukup kuat dengan tarif signifikansi $(p) 0.025(p<0.05)$. Terdapat hubungan yang bermakna antara pola makan dengan kejadian depresi pada penderita dispepsia fungsional. Kata kunci: pola makan, depresi, dispepsia fungsional
\end{abstract}

\begin{abstract}
Irregularity of meals as poor eating habits, unhurried, and irregular schedules may cause dyspepsia. Patients with depression should be treated seriously because it was feared people with depression do not pay attention to their own health so as not to comply with the diet or eating patterns become irregular. The aim of this study is to determine the relationship of diet to the incidence of depression in patients with functional dyspepsia. The research is analytic cross sectional design. The subjects were 40 people of functional dyspepsia patients. The study was conducted in the Padang City with functional dyspepsia patients using data from January to December 2011. Data collection was conducted during the period of June to November 2012 and the data processing used correlation test by computerized system. The result was the probability odds ratios (OR) with $95 \%$ Confidence Interval $(\mathrm{Cl})$ in patients with depression were 4,500 times more likely to have irregular diet compared with non-depressed ones and showed a strong degree of correlation with the significance of correlation $(p) 0.025(p<0.05)$. There is a significant relationship between the diet and the incidence of depression in patients with functional dyspepsia.
\end{abstract}

Keywords:diet, depression, functional dyspepsia

Affiliasi penulis : Fakultas Kedokteran Universitas Andalas

Korespondensi J.Perintis Kemerdekaan, Jati, Padang, 25126, Emai yurikoandre@gmail.com, Telp: (0751) 79502077, Fax : (0751) 79568841

\section{PENDAHULUAN}

Dispepsia merupakan istilah yang umum dipakai untuk suatu sindroma atau kumpulan gejala/kelu-han berupa nyeri atau rasa tidak nyaman pada ulu hati, mual, kembung, muntah, sendawa, rasa cepat kenyang, dan perut merasa penuh/begah. Keluhan tersebut dapat secara bergantian dirasakan pasien atau bervariasi baik dari segi jenis keluhan atau pun kualitasnya.

Populasi orang dewasa di Negara-negara barat yang dipengaruhi oleh dispepsia berkisar antara $14-38 \%$. Namun, sekitar $13-18 \%$ memiliki resolusi spontan selama satu tahun, dengan prevalensi yang stabil dari waktu ke waktu. ${ }^{(2)}$ Dispepsia mempengaruhi $25 \%$ dari populasi Amerika Serikat setiap tahun dan sekitar $5 \%$ dari semua penderita pergi ke dokter pelayanan primer. Sedangkan Inggris memiliki prevalensi dispepsia sekitar $21 \%$ dan hanya dua persen dari populasi tersebut berkonsultasi ke dokter pelayanan primer mereka dengan episode baru atau pertama dispepsia setiap tahun, dan dispepsia menyumbang $40 \%$ dari semua konsul ke bagian gastroenterologi. Survei pada komunitas memperkirakan bahwa hanya sekitar $35 \%$ dari penderita dispepsia yang berkonsultasi ke dokter, walaupun proporsinya akan meningkat seiring dengan bertambahnya usia. ${ }^{3}$ Berdasarkan penelitian pada populasi umum didapatkan bahwa $15-30 \%$ orang dewasa pernah mengalami dispepsia dalam beberapa hari. Negara-negara di Barat (Eropa) memiliki angka prevalensi sekitar $7-41 \%$, tetapi hanya $10-20 \%$ yang akan mencari pertolongan medis. Angka insiden dispepsia diperkirakan sekitar 1-8\%. Sedangkan di Indonesia belum didapatkan data epidemiologi yang pasti. ${ }^{4}$ Menurut data Profil Kesehatan Indonesia 2007, dispepsia sudah menempati peringkat ke-10 untuk kategori penyakit terbanyak pasien rawat inap di rumah sakit tahun 2006 dengan jumlah pasien 34.029 atau sekitar $1,59 \% .^{5}$ Sedangkan insiden kasus dispepsia kategori non-ulcer di RSUP Dr. M. Djamil yang diambil dari data IDT pada tahun 2011 sebanyak 231 orang.

Beberapa penyebab yang menimbulkan terjadinya dispepsia fungsional, yaitu faktor diet dan lingkungan, ambang rangsang persepsi, sekresi asam lambung, infeksi Helicobacter pylori. ${ }^{4}$ Ditemukan ada pengaruh pola makan terhadap dispepsia fungsional. Pola makan yang tidak teratur mungkin menjadi predisposisi untuk gejala gastrointestinal yang menghasilkan hormon-hormon gastrointestinal yang tidak teratur sehingga akan mengakibatkan terganggunya motilitas gastrointestinal. $^{6}$ 
Studi penelitian telah dilakukan mengenai pola makan yaitu hubungan antara memakan makanan tinggi karbohidrat dengan keadaan emosional yang berbeda. Penelitian tersebut menunjukkan bahwa memakan makanan tinggi karbohidrat dapat mengurangi gejala depresi. Pola makan yang tidak sehat atau tidak teratur berkorelasi dengan depresi. Selain itu, stres yang menjadi perantara terjadinya depresi bisa membuat pola makan dan gizi menjadi tambah memburuk. Studi terpisah menunjukkan bahwa stres berat dikaitkan dengan asupan makanan tinggi lemak, kurang buah dan sayuran, lebih banyak cemilan, dan penurunan frekuensi sarapan pagi. $^{7}$

Penderita depresi sangat tidak memperhatikan kesehatan dirinya seperti tidak mematuhi pola makan atau pola makannya menjadi tidak teratur, kurang latihan/olahraga, merokok. ${ }^{8}$ Selain itu, diasumsikan bahwa semakin parah tingkat episode depresi seseorang, kemungkinan besar akan terkait dengan penurunan kualitas hidup meskipun baru sedikit didapatkan bukti empiris untuk mendukung hal ini. Beberapa penelitian telah membuktikan adanya dampak pada kualitas hidup seseorang terhadap peningkatan derajat depresi seseorang. Tetapi penelitian-penelitian tersebut umumnya hanya menggunakan sampel yang terbatas dan masih belum terfokus pada perbedaan derajat depresi sesuai dengan kriteria WHO. ${ }^{9}$

Melihat begitu banyaknya angka kejadian penyakit dispepsia fungsional di dunia bahkan di Indonesia, sedangkan data mendalam tentang dispepsia fungsional masih sangat minim, khususnya di RSUP M. Djamil Padang, maka perlu dilakukan penelitian lebih lanjut tentang dispepsia fungsional. Dan seperti yang sudah diuraikan di atas, penderita depresi mengalami gangguan pola makan dan terjadi penurunan kualitas hidup sehingga gangguan pola makannya tersebut yang mencetuskan terjadinya dispepsia fungsional pada penderita yang mengalami depresi dan ditakutkan akan menambah buruk kualitas hidupnya. Hal tersebut tentu harus diintervensi agar para penderita depresi memiliki pola makan yang baik dan teratur sehingga bisa memperbaiki status psikisnya. Maka dari itu, penelitian ini lebih difokuskan untuk melihat hubungan pola makan dengan dispepsia fungsional pada penderita yang mengalami depresi.

\section{Metode}

Penelitian dilakukan di kota Padang pada bulan Juni-November 2012. Sampel dalam penelitian ini sebanyak 40 orang. Sampel merupakan penderita dispepsia fungsional dan memenuhi kriteria inklusi serta tidak memiliki kriteria eksklusi. Pemilihan sampel dilakukan dengan cara non random sampling konsekutif. Instrumen penelitian yang digunakan adalah kuesioner dispepsia untuk menilai dispepsia fungsional, Beck Depression Inventori (BDI) untuk skrining depresi, dan DSM IV untuk mendiagnosa depresi, serta kuesioner pola makan untuk menilai keteraturan pola makan subjek penelitian. Data yang diperoleh diolah dengan menggunakan sistem komputerisasi, dan untuk analisis hasil penelitiannya digunakan uji korelasi dengan tingkat pemaknaan $p<$ 0,05 .

\section{HASIL DAN PEMBAHASAN}

a. Karakteristik Subjek Penelitian

Berdasarkan frekuensi umur, jenis kelamin, tingkat pendidikan, dan pekerjaan penderita dispepsia fungsional yang dijadikan subjek penelitian ini tidak didapatkan perbedaan yang bermakna antara penderita yang mengalami depresi dengan yang tidak depresi (Tabel 1).

b. Pola Makan

Pola makan penderita dispepsia fungsional yaitu pola makan tidak teratur 23 orang $(57.5 \%)$ dan pola makan teratur 17 orang (42.5\%) (Tabel 2).

c. Analisis Bivariat

Penelitian ini mendapatkan nilai peluang Odd Ratio (OR) dengan Confidence Interval 95\% sebesar 4.500 yang artinya penderita dengan kejadian depresi berpeluang 4.500 kali lebih besar memiliki pola makan tidak teratur dari pada tidak depresi serta menunjukkan derajat hubungan yang cukup kuat dengan tarif signifikansi $(p) 0.025(p<0.05)$ (Tabel 3). Dari hasil analisa uji statistik tersebut dapat disimpulkan bahwa terdapat hubungan signifikan antara pola makan dengan kejadian depresi pada penderita dispepsia fungsional.

Penelitian yang dilakukan peneliti ini belum pernah dilakukan penelitian serupa sebelumnya untuk topik penelitian ini tetapi jika menghubungkan pola makan dengan sindroma dispepsia fungsional, maka sesuai dengan penelitian yang pernah dilakukan oleh Annisa (2009) yang menemukan hubungan signifikan antara ketidakteraturan pola makan dengan sindroma dispepsia fungsional. Selain itu juga didukung oleh hasil penelitian tentang gejala gastrointestinal yang dilakukan oleh Reshetnikov (2007), jeda antara jadwal makan yang lama dan ketidakteraturan makan berkaitan dengan gejala dispepsia. Dan berdasarkan penelitian lain oleh Ervianti (2008) tentang faktor yang berhubungan dengan kejadian sindroma dispepsia, didapatkan salah satu faktor yang berhubungan dengan kejadian sindroma dispepsia adalah keteraturan makan.

Ketidakteraturan makan seperti kebiasaan makan yang buruk, tergesa-gesa, dan jadwal yang tidak teratur dapat menyebabkan dyspepsia. ${ }^{(0)}$ Penderita depresi harus ditangani dengan sungguhsungguh karena dikhawatirkan penderita depresi sangat tidak memperhatikan kesehatan dirinya seperti tidak mematuhi pola makan atau pola makannya menjadi tidak teratur, kurang latihan/olahraga, merokok. $^{(8)}$ Berdasarkan pernyataan tersebut maka dapat disimpulkan bahwa penderita depresi yang sangat tidak memperhatikan kesehatan dirinya termasuk pola makannya yang menjadi tidak teratur tersebut yang akan menyebabkan timbulnya dispepsia fungsional pada penderita depresi.

TABEL

Tabel 1. Distribusi Frekuensi Subjek Penelitian Berdasarkan Umur, Jenis Kelamin, Tingkat Pendidikan, dan Pekerjaan

\begin{tabular}{cccccccc}
\hline \multirow{2}{*}{ KARAKTERISTIK } & \multicolumn{2}{c}{ Depresi } & \multicolumn{2}{c}{$\begin{array}{c}\text { Tidak } \\
\text { Depresi }\end{array}$} & \multicolumn{2}{c}{ Total } \\
\cline { 2 - 8 } & & $\mathrm{n}$ & $\%$ & $\mathrm{~N}$ & $\%$ & $\mathrm{n}$ & $\%$ \\
\hline \multirow{3}{*}{ UMUR } & $17-25$ th & 1 & 25.0 & 3 & 75.0 & 4 & 100.0 \\
\cline { 2 - 8 } & $26-35$ th & 1 & 25.0 & 3 & 75.0 & 4 & 100.0 \\
\cline { 2 - 8 } & $36-45$ th & 8 & 53.3 & 7 & 46.7 & 15 & 100.0 \\
\cline { 2 - 8 } & $>45$ th & 10 & 58.8 & 7 & 41.2 & 17 & 100.0 \\
\hline $\begin{array}{c}\text { JENIS } \\
\text { KELAMI } \\
\text { N }\end{array}$ & Laki-laki & 9 & 45.0 & 1 & 55.0 & 20 & 100.0 \\
\cline { 2 - 8 } & Perempuan & 11 & 55.0 & 9 & 45.0 & 20 & 100.0 \\
\hline
\end{tabular}




\begin{tabular}{cccccccc}
\hline TINGKA & Rendah & 2 & 100.0 & 0 & 0.0 & 2 & 100.0 \\
\cline { 2 - 8 } $\begin{array}{c}\text { PENDID } \\
\text { IKAN }\end{array}$ & Menengah & 9 & 60.0 & 6 & 40.0 & 15 & 100.0 \\
\cline { 2 - 8 } & Tinggi & 9 & 39.1 & 1 & 60.9 & 23 & 100.0 \\
\hline \multirow{3}{*}{$\begin{array}{c}\text { PEKER } \\
\text { JAAN }\end{array}$} & Tidak Bekerja & 13 & 59.1 & 9 & 40.9 & 22 & 100.0 \\
\cline { 2 - 7 } & PNS & 7 & 46.7 & 8 & 53.3 & 15 & 100.0 \\
\cline { 2 - 7 } & $\begin{array}{c}\text { Swasta/Wiras } \\
\text { wasta }\end{array}$ & 0 & 0.0 & 3 & 100.0 & 3 & 100.0 \\
\hline TOTAL & & 20 & & 2 & & 40 & 100.0 \\
\hline
\end{tabular}

Tabel 2. Distribusi Frekuensi Subjek Penelitian Berdasarkan Pola Makan

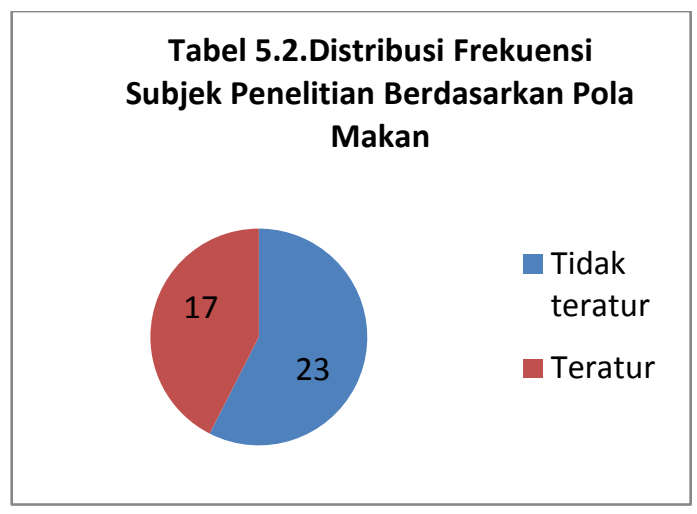

Tabel 3. Hasil Analisis Hubungan Pola Makan dengan Kejadian Depresi pada Penderita Dispepsia Fungsional

\begin{tabular}{|c|c|c|c|c|c|c|c|}
\hline \multirow{3}{*}{$\begin{array}{l}\text { Pola } \\
\text { Makan }\end{array}$} & \multicolumn{4}{|c|}{ Depresi } & $\begin{array}{l}\text { To } \\
\text { tal }\end{array}$ & \multirow{3}{*}{$\begin{array}{c}\text { OR } \\
95 \% \\
\text { Cl }\end{array}$} & \multirow{3}{*}{$P$} \\
\hline & \multicolumn{2}{|c|}{ Depresi } & \multicolumn{2}{|c|}{$\begin{array}{l}\text { Tidak } \\
\text { Depresi }\end{array}$} & \multirow[t]{2}{*}{$\mathbf{N}$} & & \\
\hline & $\mathbf{n}$ & $\%$ & $\mathbf{n}$ & $\%$ & & & \\
\hline $\begin{array}{c}\text { Tidak } \\
\text { Teratur }\end{array}$ & 15 & 65.2 & 8 & 34.8 & 23 & 4.500 & 0.025 \\
\hline Teratur & 5 & 29.4 & 12 & 70.6 & 17 & & \\
\hline Total & 20 & 100 & 20 & 100 & 40 & & \\
\hline
\end{tabular}

\section{Kesimpulan}

1. Penderita dispepsia fungsional yang mengalami depresi dijumpai lebih banyak memiliki pola makan yang tidak teratur sedangkan pada penderita dyspepsia fungsional yang tidak mengalami depresi lebih banyak memiliki pola makan teratur.

2. Karakteristik pada penderita dispepsia fungsional berdasarkan umur, jenis kelamin, tingkat pendidikan, dan pekerjaan tidak menunjukkan perbedaan yang bermakna antara penderita yang mengalami depresi dan tidak depresi.

3. Terdapat hubungan pola makan dengan kejadian depresi pada penderita dispepsia fungsional.

\section{Daftar Pustaka}

1. Djojoningrat, Dharmika. Pendekatan Klinis Penyakit Gastrointestinal .Buku Ajar : IImu Penyakit Dalam. Edisi 5. Jakarta: Balai Penerbit FK UI; 2009. hlm. 441-442.

2. Hjelland. Lifestyle aspects in functional dyspepsia : Influence of relaxation and meals on vagal activity, gastricaccommodation and symptoms (dissertation). Norway: University of Bergen; 2007.

3. Wong WM, Hu CWU, Lam CL, Hui WM, et al. Anxiety but not depression determines health care-seeking behaviourin Chinese patients with dyspepsia and irritable bowel syndrome:a population-based study. Aliment Pharmacol Ther. 2002; 16: 2081-2088.

4. Djojoningrat D. Dispepsia Fungsional.Buku Ajar : IImu Penyakit Dalam. Edisi 5. Jakarta : Balai Penerbit FK Ul; 2009. hlm. 529-532.

5. Depkes RI. Profil Kesehatan Indonesia. Jakarta : Departemen Kesehatan Republik Indonesia. 2008. hlm. 28.

6. Haapalahti M, Mykkanen $H$, Tikkanen $S$, Kokkonen J. Food habits in 10-11-year-old children with functionalgastro-intestinal disorders. European Journal of Clinical Nutrition. 2004; 58 : 1016-1021.

7. Wainer JS. Perceived Stress, Perceived Social Support, Depression and Food Consumption Frequency in College Students. Dietrich College Honors Theses. 2010; Paper 49.

8. Murni AW. Hubungan depresi dengan Infeksi Helicobacter Pylori serta Perbedaan Gambaran Histo-patologi Mukosa Lambung pada Penderita Dispepsia Fungsional (thesis). Jakarta: Universitas Indonesia. 2010; 13-16.

9. Nuevo R, et al. Impact of severity and type of depression on quality of life in cases identifyed in the community. Psychological Medicine. 2010; 40:-2069-2077.

10. Eschleman, M.M. Introductory Nutrition and Diet Therapy.Pennsylvania : Lippincott Company. 1984. hlm. 345-346. 